\title{
Regulatory differences in developmental expression of alcohol dehydrogenase are related to interspecies differences in ethanol tolerance of Drosophila
}

\author{
GOGINENI RANGANAYAKULU* \& A. R. REDDY \\ School of Life Sciences, University of Hyderabad, Hyderabad 500 134, India
}

\begin{abstract}
Biochemical properties and expression patterns of alcohol dehydrogenase were compared among members of the virilis phylad of Drosophila. Quantitative differences in stage- and tissue-specific expression of $\mathrm{ADH}$ of $D$. virilis, $D$. novamexicana, $D$. texana and $D$. americana were observed. These differences seem to correlate with the temporal differences in ethanol tolerance among these species. Quantitative differences in ADH protein levels account for most, if not all, of the activity differences between species. Analysis of the interspecific hybrids revealed that these differences arise by a mechanism affecting monomer synthesis. A comparison with earlier studies, where independently evolved regulatory differences were related to adaptations, revealed contrasting underlying mechanisms.
\end{abstract}

Keywords: adaptation, alcohol dehydrogenase, developmental expression, Drosophila, ethanol tolerance, regulatory difference.

\section{Introduction}

The existence of variation in protein coding genes (structural) and in genes (regulatory) that control their expression patterns in natural populations is evidence of past mutational events. There has been a continued effort to understand the significance of such changes in genetic composition of natural populations in adaptive evolution (for reviews see Wilson et al., 1977; MacDonald, 1983; Dickinson, 1991). While a great majority of such variations appears to be selectively neutral, evidence at the molecular level exists for the effects of positive Darwinian selection acting on both structural and regulatory genes to produce an adaptive phenotype (Crawford \& Powers, 1989; Jessen et al., 1991; Irwin et al., 1992).

The demonstration of naturally occurring structural and regulatory variation at the $A d h$ locus in populations of Drosophila and the ability of Drosophila alcohol dehydrogenase to detoxify and/or utilize environmental alcohol makes it especially amenable to studies of adaptation. Accordingly, several studies

*Correspondence: Department of Biochemistry and Molecular Biology, The University of Texas M. D. Anderson Cancer Center, 1515 Holcombe Boulevard, Houston, TX 77030, U.S.A. relate intra- and interspecific differences in $\mathrm{ADH}$ activity levels to differential utilization of ethanol rich sources (McDonald \& Avise, 1976). Consistent with this, several observations indicate that species breeding in fermenting fruits show higher ethanol tolerance than species breeding in fungi, decaying leaves and flowers (David \& van Herrewege, 1983).

Among the Drosophilids, $D$. melanogaster, $D$. lebanonensis and $D$. virilis are the three species that exhibit the highest levels of ethanol tolerance in laboratory tests (David, 1988). Therefore, analysis of ADH in these species and their closest relatives provides an opportunity to investigate the structural and regulatory changes relative to a known adaptive function. Using this approach, Dickinson et al. (1984) and Laurie et al. (1990) demonstrated that the much higher level of tolerance to ethanol in adult $D$. melanogaster than $D$. simulans is due to a difference in $\mathrm{ADH}$ expression between the species.

In the virilis phylad of Drosophila, $D$. virilis is currently cosmopolitan (Spieth, 1979) and is the most abundant species found in the breweries of Japan (Choo \& Oshima, 1974). Furthermore, populations of D. virilis exhibit latitudinal variation in ethanol tolerance patterns (David \& Kitagawa, 1982); however, its closest relatives $D$. novamexicana, $D$. texana and $D$. 
americana show limited geographical distribution and are mainly North American populations (Throckmorton, 1975). In this report, a comparative analysis of the biochemical properties and expression of $\mathrm{ADH}$ throughout development at the levels of $\mathrm{ADH}$ activity and $\mathrm{ADH}$ protein concentration among members of the virilis phylad of Drosophila has been carried out to understand the basis for their differences in ethanol tolerance limits. We show important regulatory differences in developmental expression of ADH in D. virilis and its closely related species $D$. novamexicana, $D$. texana and $D$. americana and that the regulatory differences correlate with interspecies differences in ethanol tolerance patterns.

\section{Materials and methods}

\section{Drosophila species}

D. virilis (15010.1051.0), D. novamexicana (15010. 1031.7), D. texana (15010.1041.22) and D. americana (15010.0951.0) were used in this study and were obtained from the National Drosophila Species Resource Center, Bowling Green, U.S.A. A wild-type stock of $D$. virilis was obtained from Banaras Hindu University, Varanasi, India. For comparative studies, two additional stocks of each species were also employed and have been described previously (Ranganayakulu, 1990; Ranganayakulu et al., 1991). Our stocks of Drosophila were fixed for a slow allele of alcohol dehydrogenase $\left(A d h^{\mathrm{s}}\right)$ and were used for all experiments unless otherwise noted. The isolation of a $A d h^{\mathrm{f}}$ allele of $D$. novamexicana was described earlier (Ranganayakulu et al., 1991) and was used in some of the interspecific crosses. Crosses between $D$. virilis and the rest of the species were carried out using three to four virgin females and two to three males. Flies were cultured on a standard corn meal agar medium at $25^{\circ} \mathrm{C}$. For the production of hybrids, it was critical for the medium to be fresh. The flies did not mate on old medium nor did hybrid larvae survive.

\section{Alcohol dehydrogenase activity}

The larvae or pupae or adults of a given genotype were counted, weighed and homogenized in $0.02 \mathrm{M}$ sodium phosphate buffer $p \mathrm{H} \mathrm{7.3.} \mathrm{The} \mathrm{homogenate} \mathrm{was}$ centrifuged at $15,000 \mathrm{~g}$ for $20 \mathrm{~min}$ and the supernatant was used for alcohol dehydrogenase assay. For assaying ADH activity the spectrophotometric method of Schwartz et al. (1975) was used with ethanol as substrate. ADH units are expressed as nanomoles $\mathrm{NAD}^{+}$ reduced per minute. $\mathrm{ADH}$ activity in extracts of whole organisms or tissues is also detected by electrophoresis followed by histochemical staining and quantified by densitometry (Ranganayakulu et al., 1991).

\section{Alcohol dehydrogenase purification}

Thirty to forty grams of frozen adults of each species were used for the purification of $\mathrm{ADH}$. The $\mathrm{ADH}$ purification protocol was similar to that of Sofer \& Ursprung (1968) up to the point of resuspension of the pellet after 70 per cent ammonium sulphate precipitation in $10 \mathrm{~mm}$ sodium phosphate buffer $p \mathrm{H} 6.5$. After resuspension it was dialysed extensively against the same buffer for $24 \mathrm{~h}$. The dialysed protein was loaded on a Bio-Gel HTP column previously equilibrated with the same buffer. The protein was eluted with a linear gradient of 10-300 mu phosphate buffer $p \mathrm{H} 6.5$. The protein was precipitated with 70 per cent ammonium sulphate and dialysed extensively with several changes of $50 \mathrm{~mm}$ sodium phosphate buffer. The dialysed protein was loaded on a cibacrome blue $F_{3}$ GA column and the bound protein was eluted with freshly prepared $3 \mathrm{~mm}$ NAD. Fractions showing ADH activity were detected by a spot test employing the histochemical stain mixture. Those fractions showing substantial $\mathrm{ADH}$ activity were pooled and immediately dialysed against several changes of double distilled water overnight. The dialysed sample was freeze-dried and stored at $-20^{\circ} \mathrm{C}$.

\section{SDS-PAGE}

Polyacrylamide electrophoresis in the presence of SDS was performed using 15 per cent gel slabs as described by Laemmli (1970). After the electrophoresis the gels were washed with 7.5 per cent acetic acid for $30 \mathrm{~min}$ and stained with 0.1 per cent Coomassie blue R-250 in 50 per cent methanol and 75 per cent acetic acid for $4 \mathrm{~h}$ and destained with a solution containing 5 per cent methanol and 75 per cent acetic acid.

\section{Molecular weight determination}

The molecular weight of the ADH subunits was estimated by SDS-PAGE according to the procedure of Weber et al. (1972) using bovine serum albumin, ovalbumin, carbonic anhydrase, trypsin inhibitor and lactalbumin as molecular weight standards.

\section{Protein estimation}

Protein concentrations were determined using the Biorad protein assay reagents using bovine serum albumin as standard. 


\section{Enzyme kinetics}

Michaelis-Menton constants for ethanol were determined for purified ADH from different species using the standard assay for ADH with varying concentrations of ethanol. The apparent $\mathrm{K}_{\mathrm{m}}$ was estimated by a least squares regression fit.

\section{Thermal stability of alcohol dehydrogenase}

The pure enzyme solution was diluted to a concentration of $200 \mu \mathrm{g} \mathrm{ml}^{-1}$ with $0.02 \mathrm{M}$ sodium phosphate buffer $p \mathrm{H} 7.5$ and incubated in a water bath at $45^{\circ} \mathrm{C}$. At intervals of $10 \mathrm{~min}$ aliquots were withdrawn and assayed using the standard assay procedure. Control enzyme assays were carried out with enzyme samples that were not subjected to heat treatment. The thermal stability of the enzyme was determined by measuring the loss of enzyme activity on heating compared with the control values. All assays were duplicated and two replicates of each sample were tested in each experiment.

\section{Immunological methods}

Production of polyclonal antisera. Polyclonal antibodies to purified $D$. virilis ADH were raised in New Zealand White rabbits. Briefly, the lyophilized ADH protein was dissolved in $50 \mathrm{~mm}$ sodium phosphate buffer $p \mathrm{H} 7.0$ containing 0.9 per cent $\mathrm{NaCl}$ and 500 $\mu \mathrm{g}$ of such protein was emulsified in an equal volume of Freund's complete adjuvant and injected subcutaneously at multiple sites. After 4 weeks, two boosts at intervals of 1 week were given. Blood samples were collected after the final boost from the ear vein in centrifuge tubes. After allowing to stand at room temperature for $2-3 \mathrm{~h}$ and overnight at $4^{\circ} \mathrm{C}$ without disturbing, the blood clot was allowed to settle by centrifuging in a clinical centrifuge at maximum speed for $10 \mathrm{~min}$. To the yellowish serum, 0.1 per cent Thimersol was added and stored at $-20^{\circ} \mathrm{C}$ as $100 \mu \mathrm{l}$ aliquots.

Estimation of cross-reacting material. ADH crossreacting material was estimated by the radial immunodiffusion method of Mancini et al. (1965) using antiserum at a 1 per cent final concentration. Forty organisms of each developmental stage (actively feeding third instar larvae, late pupae (eyes and wing pads visible) or adults of a given age) were homogenized in

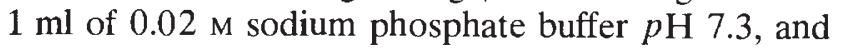
spun at 7000 r.p.m. in a cooling microfuge for $10 \mathrm{~min}$. Ten microlitres of supernatant were placed in $3 \mathrm{~mm}$ wells and allowed to diffuse for $48 \mathrm{~h}$ at $4^{\circ} \mathrm{C}$ and the precipitin rings were visualized using the ADH histochemical stain. The relative CRM levels were directly read from a standard curve $(r=0.99)$ obtained by plotting ring diameter against log concentration of antigen (Fahey \& Mckelvey, 1965). D. virilis ADH was used as antigen for the standard curve. Furthermore, a single radial immunodiffusion experiment performed with a defined quantity of purified $\mathrm{ADH}$ from each species showed no significant variation in the ring diameter.

\section{Ethanol tolerance tests}

Adult fly cultures were subjected to ethanol treatment according to the method of David \& Bocquet (1977). Larvae were tested for survival on ethanol supplemented media. Briefly, adult flies were allowed to lay eggs on agar plates and hatched first instar larvae were transferred to instant Drosophila medium (Carolina Biological) supplemented with ethanol. Cultures maintained without ethanol (but with 2 per cent sucrose or instant medium) served as control.

\section{Results}

\section{Developmental programme}

The developmental profiles for $\mathrm{ADH}$ activity in $D$. virilis, $D$. novamexicana, $D$. americana and $D$. texana are shown in Fig. 1. It is clear from the data that the activity increases during larval development until the third instar stage, then falls off rapidly during the pupal stage and begins to rise again at eclosion. Even though these species show developmental profiles of similar shape there are significant quantitative differences. Firstly, of the tested species $D$. virilis consistently has higher activity at the larval and adult stages of development. Secondly, between 2 and 4 days post-eclosion $D$. virilis shows a rapid increase of $\mathrm{ADH}$ activity over other species.

Although the differences in levels of ADH activity observed in these species using crude enzyme extracts are informative, a quantitative comparison of the $\mathrm{ADH}$ protein levels reflects the underlying gene activity. To this end polyclonal antibodies were raised against the purified $D$. virilis ADH. These antibodies were shown to produce single and continuous precipitin lines on cross-reaction with the antigen from the rest of the species (Ranganayakulu et al., 1991). Utilizing this antiserum the ADH protein concentrations were determined by the single radial immunodiffusion method. From the results presented in Table 1, it is clear that $D$. virilis and $D$. americana show the highest amounts of $\mathrm{ADH}$ protein at the third instar larval stage. In all 
Fig. 1 Developmental time course of ADH activity. Each point represents the mean of determinations made on four separate extracts. (অ) D. virilis; $\diamond$, D. novamexicana; $\square$, D. texana and $\bullet$, D. americana. The eclosion times at $25^{\circ} \mathrm{C}$ after oviposition for $D$. virilis, $D$. novamexicana, $D$. texana and $D$. americana are 13.5, 13.0, 13.0 and 15.5 days, respectively.

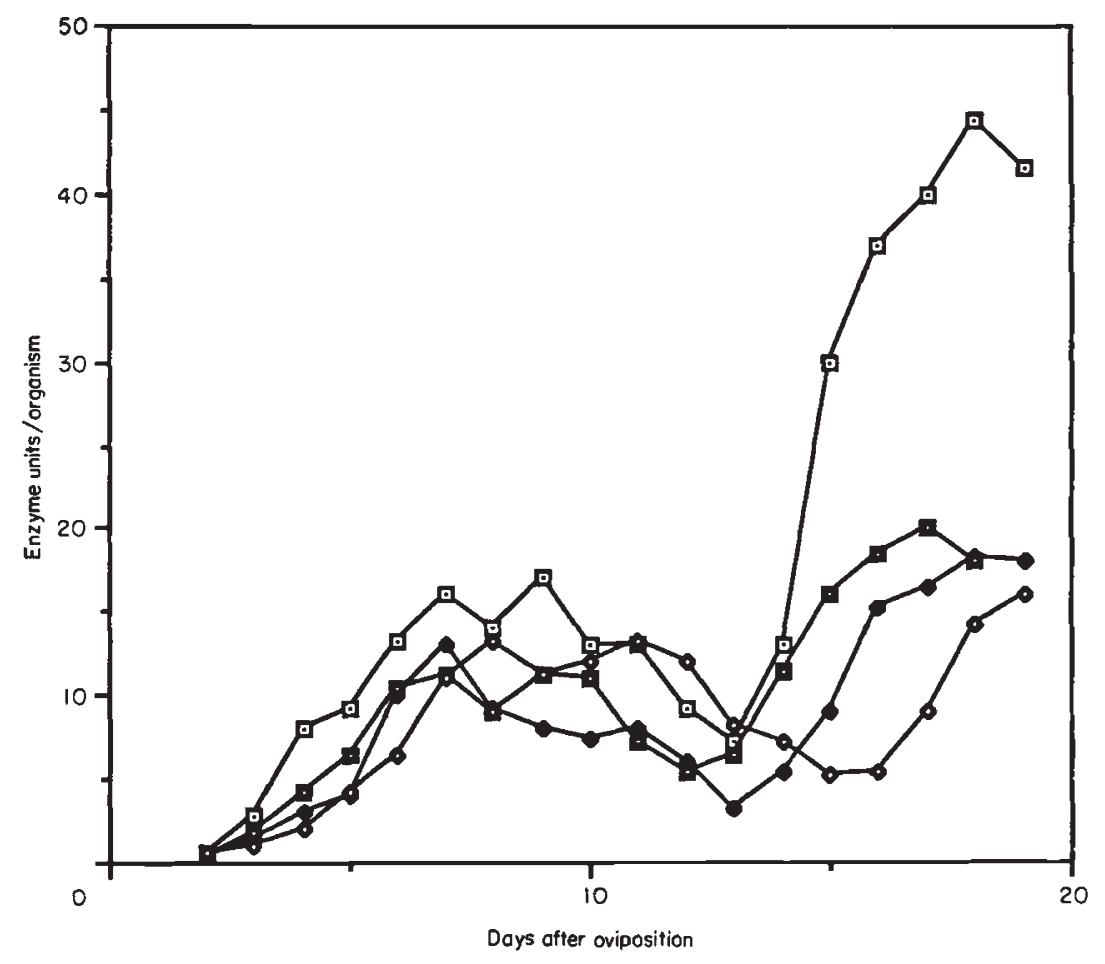

Table 1 Relative CRM levels at different developmental stages

\begin{tabular}{lcccc}
\hline & \multicolumn{4}{c}{ Developmental stage } \\
\cline { 2 - 5 } & & & \multicolumn{2}{c}{ Adults } \\
\cline { 4 - 5 } Species & $\begin{array}{c}\text { III instar } \\
\text { larvae }\end{array}$ & Pupae & 2-day-old & 5-day-old \\
\hline D. virilis & 0.28 & 0.08 & 0.89 & 1.00 \\
& $(7.3 \pm 0.23)$ & $(4.5 \pm 0.11)$ & $(10.1 \pm 0.29)$ & $(10.5 \pm 0.23)$ \\
D. novamexicana & 0.14 & 0.10 & 0.08 & 0.37 \\
& $(5.6 \pm 0.14)$ & $(5.0 \pm 0.11)$ & $(4.6 \pm 0.18)$ & $(7.8 \pm 0.36)$ \\
D. texana & 0.25 & 0.09 & 0.14 & 0.30 \\
& $(6.9 \pm 0.18)$ & $(4.6 \pm 0.13)$ & $(5.6 \pm 0.11)$ & $(7.2 \pm 0.17)$ \\
D. americana & 0.27 & 0.07 & 0.17 & 0.20 \\
& $(7.2 \pm 0.15)$ & $(4.3 \pm 0.14)$ & $(6.2 \pm 0.15)$ & $(6.7 \pm 0.22)$ \\
& & & &
\end{tabular}

All values are expressed relative to $D$. virilis adult CRM levels. Values in parentheses represent mean ring diameter and standard error of triplicate samples.

species pupae show lower levels of $\mathrm{ADH}$ protein than those of larvae. Futhermore, it was observed that the 2-day-old $D$. virilis adults show almost tenfold higher levels of ADH protein than that of pupae. On the other hand, the rest of the species show either equal or nearly twofold higher $\mathrm{ADH}$ protein over their respective pupal levels. There is a gradual increase in all species in their $\mathrm{ADH}$ protein level up to the fifth day stage but their level remains significantly lower than that of $D$. virilis. The CRM profiles corroborate the observed differences in the developmental profiles of $\mathrm{ADH}$ activity. Thus it is clear that the fluctuations in the activity of $\mathrm{ADH}$ during development are reflected in the steady-state levels of ADH protein. These differences in steady-state levels of $\mathrm{ADH}$ protein found in the standard stocks used in preceding experiments are widespread in the respective species. We tested at least two additional stocks (all $A d h^{s}$ ) of each species and found no significant differences compared with the standard stocks (Ranganayakulu, 1990). 

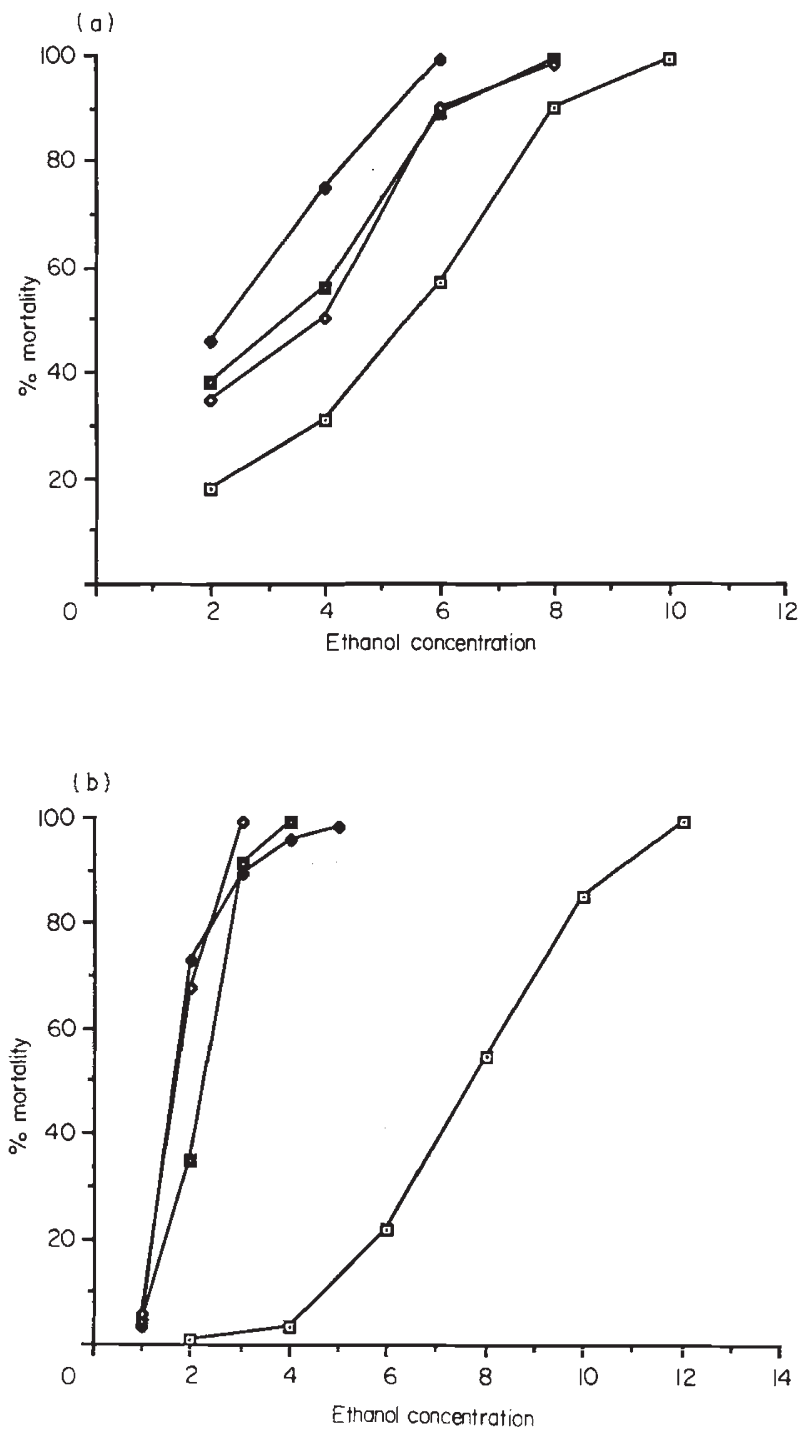

Fig. 2 Mortality on ethanol. (a) Larvae were scored as percentage survived to eclosion. (b) Adult mortality after 2 days of exposure to various concentrations of ethanol. $\bullet, D$. virilis; $\bullet$, D. novamexicana; $\mathbf{\bullet}$, D. texana; and $\bullet D$. americana.

\section{Ethanol tolerance}

As ADH is involved in the detoxification of alcohols, the larvae and adults of these species were subjected to alcohol treatments of various concentrations to test whether there is any correlation in $\mathrm{ADH}$ activity levels and ethanol tolerance limits. From the results presented in Fig. 2 it is clear that among the tested species $D$. virilis has the highest tolerance. Furthermore, these differences are much more striking at the adult stage. Thus the species-specific differences in ADH activity levels during development may be significant in terms of adaptation of these species to alcohol environments.

\section{Characterization of the $A D H$ protein}

As the activity differences between species represent differences in the steady-state level of the $\mathrm{ADH}$ protein, it is instructive to assess the structural relatedness of the protein from each species. As the first step, the enzyme from each species was purified and the purity of the samples was judged by SDS-PAGE. In all cases they were found to be greater than 90 per cent pure (data not shown). The pure enzyme solution was used to determine some biochemical features of $\mathrm{ADH}$ in different species. From the results presented in Table 2, it is clear that D. americana and D. texana show similar Michaelis constants and $p \mathrm{H}$ optima. Even though $D$. virilis and D. novamexicana have nearly identical $\mathrm{K}_{\mathrm{m}}$ values, their $p \mathrm{H}$ optima values are different. Among these species, $D$. virilis is the only species with two $p \mathrm{H}$ optima values. Furthermore, the thermal stability of ADH from each species is shown in Fig. 3. The enzymes clearly differ in their stability patterns suggesting differences in the primary structure of the protein.

Table 2 Biochemical properties of ADH

\begin{tabular}{|c|c|c|c|c|}
\hline \multirow[b]{2}{*}{ Species } & \multirow{2}{*}{$\begin{array}{l}\text { Subunit } \\
\text { molecular } \\
\text { weight }\end{array}$} & \multirow[b]{2}{*}{$\begin{array}{c}p \mathrm{H} \\
\text { optima }\end{array}$} & \multicolumn{2}{|c|}{ Ethanol kinetic parameters $\dagger$} \\
\hline & & & $\begin{array}{c}\mathrm{K}_{\mathrm{m}}(\mathrm{app}) \\
(\mathrm{mM})\end{array}$ & $\begin{array}{l}\mathrm{V}_{\text {max }}(\text { app }) \times 10^{3} \\
\text { units } / \text { mg protein }\end{array}$ \\
\hline D. virilis & 27800 & $8.5,10.0$ & $5.83 \pm 0.19$ & $5.07 \pm 0.12$ \\
\hline D. novamexicana & 27800 & 9.5 & $5.35 \pm 0.32$ & $2.50 \pm 0.11$ \\
\hline D. texana & 27800 & 9.0 & $7.28 \pm 0.21$ & $2.67 \pm 0.10$ \\
\hline D. americana & 27800 & 9.0 & $7.68 \pm 0.32$ & $2.51 \pm 0.17$ \\
\hline
\end{tabular}

$\lceil$ Each value represents mean and standard error of three independent

determinations and values are calculated according to Lineweaver \& Burk (1934). 


\section{Tissue-specific expression of $A D H$}

The fact that there are substantial quantitative differences both in ADH activity and CRM level between species raises the pertinent question as to whether these differences exist uniformly in all tissues. In order to define the expression of ADH, different tissues from individual organisms were dissected out from larvae as well as adults and their ADH levels were quantified by electrophoretic separation and densitometry. These results were corroborated by estimating the CRM levels of individual organs (Tables 3 and 4). Speciesspecific differences in larval tissues are clearly evident in that $D$. virilis shows higher activity in anterior midgut and fatbody whereas $D$. americana shows highest

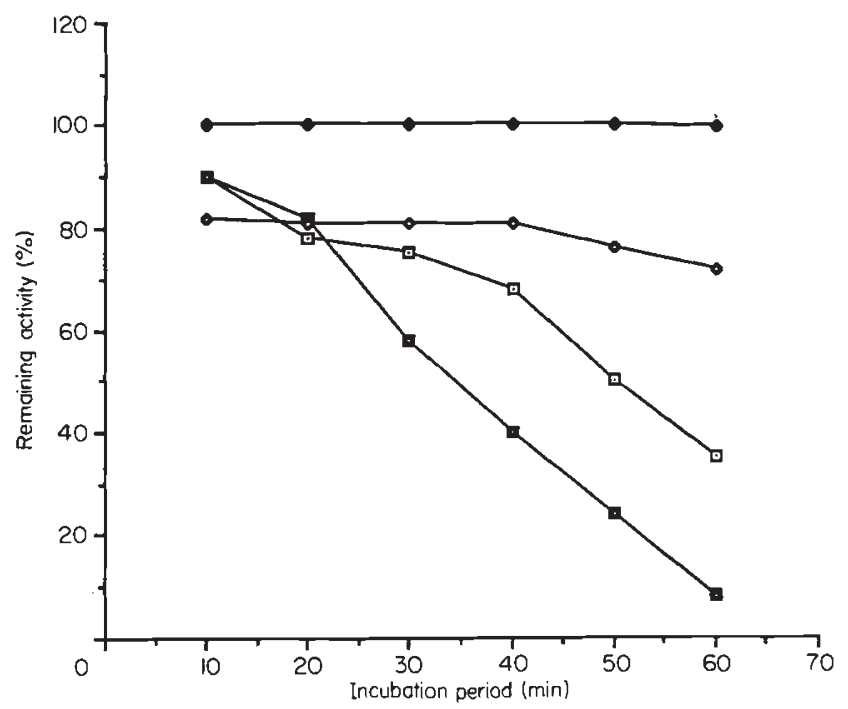

Fig. 3 Thermal stability of purified alcohol dehydrogenase at $45^{\circ} \mathrm{C}$. $D$. virilis, $\diamond$ D. novamexicana, $D$. texana, $\diamond D$. americana. activity in midgut and caracass. On the other hand, at the adult stage $D$. virilis shows highest activity in all the tested tissues. When a comparison was made of CRM levels of three larval tissues and four adult tissues the patterns were found to be similar to those of gel scanning patterns.

\section{Genetic basis of activity variation}

The quantitative variation in CRM could result from differences in synthesis or turnover of the gene product resulting in an altered steady-state level. A distinction between these alternatives can be made by analysing the activity patterns in interspecific hybrids. From the results presented in Table 5 it is clear that activity patterns of interspecific hybrids are suggestive of additive inheritance but in $D$. virilis $\times D$. novamexicana $F_{1}$ hybrids, the activity per organism is much lower than the midparent value. This appears to be a strainspecific phenomenon because in crosses with other stocks of $D$. novamexicana the $\mathrm{F}_{1}$ hybrids show strict additive inheritance (Ranganayakulu, 1990). If activity patterns were to be determined by post-translational enzyme degradation under trans-acting control, inheritance patterns of a dominant recessive nature would be obtained (Ganschow \& Schimke, 1969; Lai \& Scandalios, 1980; King \& McDonald, 1983). Thus these results suggest that the differences are likely to be arising out of differences in enzyme synthesis.

As the allozymes coded by $D$. virilis and $D$. novamexicana differ in electrophoretic mobility patterns a strategy designed by Dickinson (1980) was used to compare the relative expression of the alleles in interspecific hybrids. From the results shown in Fig. 4 it is clear that the allozyme characteristic of $D$. virilis is predominantly expressed. Furthermore, the subunit

Table 3 Relative ADH activity levels in different tissues of larvae and adults

\begin{tabular}{|c|c|c|c|c|c|c|c|c|}
\hline \multirow[b]{2}{*}{ Species } & \multicolumn{4}{|c|}{ Larval tissue $†$} & \multicolumn{4}{|c|}{ Adult tissue $\ddagger$} \\
\hline & $\begin{array}{c}\text { Anterior } \\
\text { midgut }\end{array}$ & Midgut & Fatbody & Carcass & Head & Midgut & Hindgut & Fatbody \\
\hline D. virilis & 1.00 & 1.00 & 1.00 & 1.00 & 1.00 & 1.00 & 1.00 & 1.00 \\
\hline D. novamexicana & $0.30 \pm 0.10$ & $0.80 \pm 0.13$ & $0.30 \pm 0.10$ & $1.00 \pm 0.09$ & $0.47 \pm 0.08$ & $0.19 \pm 0.07$ & $0.22 \pm 0.07$ & $0.41 \pm 0.09$ \\
\hline D. texana & $0.13 \pm 0.05$ & $1.05 \pm 0.15$ & $0.64 \pm 0.17$ & $0.51 \pm 0.08$ & $0.52 \pm 0.11$ & $0.54 \pm 0.12$ & $0.25 \pm 0.08$ & $0.25 \pm 0.07$ \\
\hline D. americana & $0.21 \pm 0.06$ & $1.99 \pm 0.26$ & $0.70 \pm 0.12$ & $1.00 \pm 0.15$ & $0.26 \pm 0.08$ & $0.29 \pm 0.08$ & $0.37 \pm 0.10$ & $0.13 \pm 0.06$ \\
\hline
\end{tabular}

$\dagger$ Actively feeding third instar larvae were used as source of organs. In each case 15 anterior midguts, 8 midguts, 3 caracasses or fatbodies of three larvae were homogenized in $30 \mu \mathrm{l}$ buffer, centrifuged at $1000 \mathrm{r} . \mathrm{p} . \mathrm{m}$. for $2 \mathrm{~min}$ at $4^{\circ} \mathrm{C}$ and $3 \mu \mathrm{l}$ of the supernatant was used for activity assay or for the determination of CRM levels.

$\ddagger 3-6$-day-old adults were used as source of organs. In each case, 4 heads, 20 midguts, 20 hindguts or fatbodies (along with abdominal bodywall) of two adults were homogenized in $30 \mu 1$ buffer and processed as above.

All values are expressed relative to $D$. virilis tissue activity levels. 
Table 4 Relative ADH protein levels in different tissues of larvae and adults

\begin{tabular}{|c|c|c|c|c|c|c|c|}
\hline \multirow[b]{2}{*}{ Species } & \multicolumn{3}{|c|}{ Larval tissue } & \multicolumn{4}{|c|}{ Adult tissue } \\
\hline & $\begin{array}{l}\text { Anterior } \\
\text { midgut }\end{array}$ & Midgut & Fatbody & Head & Midgut & Hindgut & Fatbody \\
\hline D. virilis & 1.00 & 1.00 & 1.00 & 1.00 & 1.00 & 1.00 & 1.00 \\
\hline & $(11.0 \pm 0.47)$ & $(11.1 \pm 0.36)$ & $(11.0 \pm 0.31)$ & $(9.5 \pm 0.35)$ & $(7.4 \pm 0.21)$ & $(7.0 \pm 0.12)$ & $(11.2 \pm 0.54)$ \\
\hline D. novamexicana & $\begin{array}{c}0.22 \\
(77+012)\end{array}$ & $\begin{array}{c}0.86 \\
(10.4 \pm 0.18)\end{array}$ & $\begin{array}{c}0.23 \\
(7.6+0.24)\end{array}$ & $\begin{array}{c}0.53 \\
(8.0+0.23)\end{array}$ & $\begin{array}{c}0.21 \\
(45+021)\end{array}$ & 0.27 & $\begin{array}{c}0.32 \\
(90+0.31)\end{array}$ \\
\hline D. texana & $\begin{array}{c}1.1 \pm 0.12) \\
0.10\end{array}$ & $\begin{array}{c}(10.4 \pm 0.18) \\
1.13\end{array}$ & $\begin{array}{c}(.0 \pm 0.24) \\
0.71 \\
(91+0.18)\end{array}$ & $\begin{array}{c}(0.0 \pm 0.23) \\
0.45 \\
(76+0.24)\end{array}$ & $\begin{array}{c}(4.5 \pm 0.21) \\
0.64 \\
(6.5+0.18)\end{array}$ & $\begin{array}{c}(4.2-10.12) \\
0.27\end{array}$ & $\begin{array}{c}(9.0 \pm 0.20 \\
0.20 \\
(8.0 \pm 0.30)\end{array}$ \\
\hline D. americana & $\begin{array}{c}0.20 \\
(7.6 \pm 0.17)\end{array}$ & $\begin{array}{c}2.10 \\
(12.2 \pm 0.23)\end{array}$ & $\begin{array}{c}(9.1 \pm 0.10) \\
0.68 \\
(10.1 \pm 0.18)\end{array}$ & $\begin{array}{c}0.19 \\
(5.4 \pm 0.21)\end{array}$ & $\begin{array}{c}(0.5 \pm 0.18) \\
0.28 \\
(4.7 \pm 0.16)\end{array}$ & $\begin{array}{c}(4.4 \pm 0.08) \\
0.36 \\
(4.7 \pm 0.07)\end{array}$ & $\begin{array}{c}(8.0 \pm 0.50) \\
0.10 \\
(6.6 \pm 0.20)\end{array}$ \\
\hline
\end{tabular}

Values in parentheses represent mean ring diameter and standard error of triplicate values.

For sample preparation see footnotes of Table 3. For each set of determinations $D$. virilis tissue ADH levels were used as standards $(1.00)$ and all other values are relative.

Table 5 ADH activity levels of parents and hybrids

\begin{tabular}{lcccc}
\hline & \multicolumn{3}{c}{ Developmental stage } \\
\cline { 2 - 5 } & \multicolumn{2}{c}{ Larvae } & \multicolumn{2}{c}{ Adults } \\
\cline { 2 - 5 } Species & $\begin{array}{c}\text { Activity per } \\
\text { organism }\end{array}$ & $\begin{array}{c}\text { Specific } \\
\text { activity }\end{array}$ & $\begin{array}{c}\text { Activity per } \\
\text { organism }\end{array}$ & $\begin{array}{c}\text { Specific } \\
\text { activity }\end{array}$ \\
\hline Parents & & & & \\
D. virilis & $18.0 \pm 3.0$ & $92.0 \pm 7.5$ & $35.0 \pm 5.0$ & $157.0 \pm 14.0$ \\
D. novamexicana $\left(\right.$ Adh $\left.h^{s}\right)$ & $10.0 \pm 2.0$ & $52.0 \pm 5.0$ & $13.0 \pm 2.3$ & $48.0 \pm 5.7$ \\
D. texana & $14.0 \pm 1.6$ & $56.0 \pm 4.0$ & $19.0 \pm 2.3$ & $57.0 \pm 7.0$ \\
D. americana & $16.0 \pm 3.0$ & $47.0 \pm 5.7$ & $16.0 \pm 1.6$ & $49.0 \pm 5.0$ \\
F, hybrids & $15.0 \pm 2.3$ & $68.0 \pm 6.5$ & $18.0 \pm 3.3$ & $100.0 \pm 9.3$ \\
D. virilis $\times$ D. novamexicana $\left(\right.$ Adh $\left.h^{s}\right)$ & $(14.0)$ & $(72.0)$ & $(24.0)$ & $(102.5)$ \\
D. virilis $\times$ D. texana & $16.0 \pm 1.6$ & $78.0 \pm 6.3$ & $27.0 \pm 5.3$ & $104.0 \pm 6.9$ \\
D. virilis $\times$ D. americana & $(16.0)$ & $(74.0)$ & $(27.0)$ & $(107.0)$ \\
& $17.0 \pm 2.3$ & $62.0 \pm 4.6$ & $20.0 \pm 2.7$ & $107.0 \pm 11.0$ \\
& $(17.0)$ & $(69.5)$ & $(25.5)$ & $(103.0)$ \\
\hline
\end{tabular}

Values in parentheses represent expected results from additive inheritance patterns and are predicted by the mean of the two parental values.

ratios observed in the hybrid are in good agreement with those predicted from the activity differences of the parents, suggesting that the activity differences are entirely consistent with a mechanism affecting monomer synthesis.

\section{Discussion}

The data presented in this report show differences in temporal patterns of ethanol tolerance among closely related species of the virilis group of Drosophila. These differences seem to be related to the observed quantitative differences in ADH levels of these species. Similar conclusions have been reached for other Drosophila species (McKenzie \& Parsons, 1972; McDonald \& Avise, 1976; Dickinson et al., 1984). To determine the regulatory versus structural basis of such interspecific differences in ADH levels, a comparative analysis of the biochemical properties and expression patterns of ADH has been carried out. The immunological data strongly suggest that most, if not all, of the activity variation between species is accounted for by 


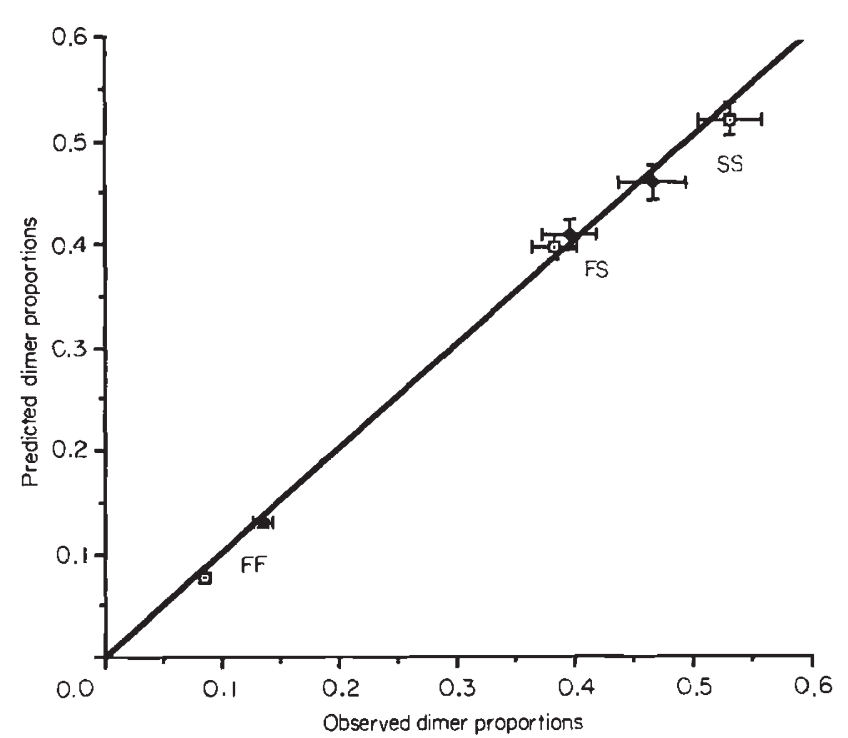

Fig. 4 Regression analysis of observed and predicted dimer proportions of allelic enzymes in hybrids of $D$. virilis $\times D$. novamexicana $\left(A d h^{\mathrm{f}}\right)$. The $\mathrm{x}$-axis represents the dimer proportions measured in hybrids by densitometry. The y-axis represents the dimer proportions predicted by the binomial theorem from relative activity ratios of the parents measured by electrophoresis of mixed samples. Bars represent standard errors of four determinations. The line drawn has a slope of 1.00 and represents the line on which the data would lie if the observed and predicted dimer proportions matched perfectly. $\bullet$, III instar larve; $\square$, adults.

variation in the concentration of $\mathrm{ADH}$ protein. Furthermore, such differences were found to be stageand tissue-specific. It is interesting to note that such differences in quantitative levels of $\mathrm{ADH}$ are more pronounced at the adult stage than at the larval stage. These differences seem to arise by a difference in relative rates of synthesis in these species. The additive inheritance of activity patterns and the observed good correlation of dimer ratios in interspecific hybrids are consistent with such a conclusion; however, a detailed analysis of the interspecific hybrids of $D$. virilis $/ D$. novamexicana revealed subtle differences that specifically affect the heterodimer stability in the adult head and hindgut tissues (G. Ranganayakulu \& A. R. Reddy, unpublished data).

From a biochemical characterization of the $\mathrm{ADH}$ protein, it is evident that the ADH present in these species has identical molecular weight but differences found in $\mathrm{pH}$ optima and kinetic parameters represent structural differences. Although it is difficult to assess the biological significance of these differences they at least indicate the existence of differences in the catalytic site of ADH among these species. David \& Kitagawa (1982), however, attributed the high ethanol tolerance in $D$. virilis to a highly active $\mathrm{ADH}$, based on spectrophotometric and electrophoretic assays. Similarly, Juan \& Gonzalez-Duarte (1981) found a closer similarity in ethanol kinetic parameters of ADH between $D$. virilis and $D$. melanogaster and interpreted it as an adaptation to the ecology of the species.

Our central'conclusion from the present study is that there seems to be increased ethanol tolerance in $D$. virilis over its closely related species based largely, but not completely, on a change in gene regulation. In many ways this looks like a situation parallel to the comparison made earlier between $D$. melanogaster and D. simulans (Dickinson et al., 1984) where the differences in Adh expression arise due to one or more trans-acting genes (Laurie et al., 1990). In the present case simple genetic mechanisms all under cis-control seem to account for such differences. A similar analysis of ADH expression in D. lebanonensis and its closely related species should be interesting. The recruitment of lysozyme in the stomach of ruminants and colobine monkeys is another good example of convergent adaptive evolution (Stewart et al., 1987). In this case, the large-scale production of lysozyme by the stomach lining involved gene duplication as well as a regulatory change in gene expression (Dobson et al., 1984; Irwin et al., 1989).

Among these species, the enzyme ADH is coded by homologous genes (Ranganayakulu et al., 1991) and yet significant differences in biochemical properties and stage-specific expression of $\mathrm{ADH}$ were found. These differences are much more striking between $D$. virilis and the rest of the species. It is tempting to speculate that this is a clear case of adaptive evolution. Consistent with this are the observations that $D$. virilis is often collected from breweries and seems to be attracted by alcohol-rich environments (Choo \& Oshima, 1974; Spieth, 1979); however, the natural habitat of these species seems to be the rotting bark of a limited number of deciduous tree species which is not likely to contain a high amount of alcohol (Throckmorton, 1975). This suggests that high ethanol tolerance in $D$. virilis may be a recently evolved mechanism for adaptation to alcohol-rich habitats. In general, ethanol as a selective agent can act either at the preadult or adult stages of Drosophila. It was shown earlier that in $D$. melanogaster, the adaptation to ethanol-rich media was mainly accomplished during the juvenile life stages and that the maternal ADH has a significant role in that process (Kerver \& van Delden, 1985; Kerver \& Rotman, 1987). In the virilis phylad of Drosophila, ADH is not maternally encoded and zygotic transcription of $A d h$ is not seen until the 24th hour of embryogenesis (G. Ranganayakulu, unpublished data). Therefore, in these species, if ethanol tolerance is related more to adult exposure to 
ethanol vapour during feeding and/or oviposition than to larval resources, one would expect to see more differences in patterns of expression of $\mathrm{ADH}$ at the adult stage than at the larval stage. The results presented in this report are consistent with such a conclusion.

Finally, a complete understanding of the signficance of interspecific differences in ADH activity will depend on clarification of the processes by which they are established, including an adequate description of the intraspecific variants that might serve as raw material for evolution of fixed differences. In view of this, alcohol dehydrogenase expression was analysed in three stocks of each species of the virilis phylad of Drosophila and only in D. virilis were quantitative variants associated with tissue-specific differences in ADH expression identified (Ranganayakulu, 1990; Ranganayakulu et al., 1991). Earlier studies, however, on chromosome substitution lines in $D$. melanogaster suggest that quantitative variation in enzyme activity is common and extensive between lines (Laurie-Ahlberg et al., 1980, 1982). It follows then that a detailed analysis of ADH similar to the one in the present study employing a wide variety of stocks of each species of the virilis phylad of Drosophila is needed for an evaluation of the adaptive significance of such polymorphisms.

\section{Acknowledgements}

We thank Professor W. J. Dickinson for several helpful suggestions and anonymous reviewers for insightful comments on the manuscript. G. R. thanks CSIR (India) for financial assistance.

\section{References}

CHOO, J. K. AND OSHIMA, C. 1974. Phototactic selection and its effect on some quantitative characters of Drosophila virilis. Environ. Control Biol., 12, 41-51.

CRAWFORD, D. L. AND POWERS, D. A. 1989. Molecular basis of evolutionary adaptation at the lactic dehydrogenase-B locus in the fish Fundulus heteroclitus. Proc. Natl. Acad. Sci. U.S.A., 86, 9365-9369.

DAVID, J. R. 1988. Ethanol adaptation and alcohol dehydrogenase polymorphism in Drosophila: from phenotypic functions to genetic structures. In: de Jong, G. (ed.) Population Genetics and Evolution, pp. 163-172. Springer-Verlag, Berlin.

DAVID, J. R. AND BOCQUET, C. 1977. Genetic tolerance to ethanol in Drosophila melanogaster; increase by selection and analysis of correlated responses. Genetica, 47, 43-48.

DAVID, J. R. AND VAN HeRreWEGE, J. 1983. Adaptation to alcoholic fermentation in Drosophila species: relationship between alcohol tolerance and larval habitat. Comp. Biochem. Physiol., 74A , 283-288.
DAVID, J. R. AND KITAGaWA, O. 1982. Possible similarities in ethanol tolerance and latitudinal variations between Drosophila virilis and Drosophila melanogaster. Jpn. J. Genet., 57, 89-95.

DiCKINSON, w. J. 1980. Complex cis-acting regulatory genes demonstrated in Drosophila hybrids. Dev. Genet., 1, 229-240.

DICKINSON, w. J. 1991. The evolution of regulatory genes and patterns in Drosophila. Evol. Biol., 25, 127-173.

DICKINSON, W. J., ROWAN, R. G. AND BRENNAN, M. D. 1984. Regulatory gene evolution: adaptive differences in expression of alcohol dehydrogenase in Drosophila melanogaster and Drosophila simulans. Heredity, 52, 21 5-225.

DOBSON, D. E., PRAGER, E. M. AND WILSON, A. C. 1984. Stomach lysozymes of ruminants. I. J. Biol. Chem., 259 , $11607-11616$.

FAHEY, J. AND MCKELVEY, E. 1965. Quantitative determination of serum immunoglobulins in antibody agar plates. $J$. Immunol., 94, 84-90.

GANSCHOW, R. AND SCHIMKE, R. T. 1969. Independent genetic control of the catalytic activity and the rate of degradation of catalase in mice. J. Biol. Chem., 244, 4649-4658.

IRWIN, D. M., PRAGER, E. M. AND WILSON, A. C. 1992. Evolutionary genetics of ruminant lysozymes. An. Genet., 23, 193-202.

IRWIN, D. M., SIDOW, A., WHITE, R. T. AND WILSON, A. C. 1989. Multiple genes for ruminant lysozymes. In: Smith-Gill, S. J. and Sercarz, E. E. (eds) The Immune Response to Structurally Defined Proteins: The Lysozyme Model, pp. 73-85. Adenine Press, New York.

JESSEN, T., WEBER, R. E., FERMI, G., TAME, J. AND BRAUNITZER, G. 1991. Adaptation of bird haemoglobins to high altitudes: demonstration of molecular mechanism by protein engineering. Proc. Natl. Acad. Sci. U.S.A., 88, $6519-6522$.

JUAN, E. AND GONZALEZ-DuARTE, R. 1981. Determination of some biochemical and structural features of alcohol dehydrogenase from $D$. melanogaster, $D$. simulans and $D$. virilis. Biochem. J., 195, 61-69.

KERVER, J. W. M. AND ROTMAN, G. 1987. Development of ethanol tolerance in relation to the alcohol dehydrogenase locus in Drosophila melanogaster. 11. The influence of phenotypic adaptation and maternal effect on survival on alcohol supplemented media. Heredity, 58, 239-248.

KERVER, J. W. M. AND VAN DELDEN, w. 1985. Development of tolerance to ethanol in relation to the alcohol dehydrogenase locus in Drosophila melanogaster. I. Adult and eggto-adult survival in relation to ADH activity. Heredity, 55, 355-367.

KING, J. J. AND MCDONALD, J. F. 1983. Genetic localization and biochemical characterization of a trans-acting regulatory effect in Drosophila. Genetics, 105, 55-69.

LAEMMLI, U. K. 1970. Cleavage of structural proteins during the assembly of the head of bacteriophage T4. Nature, 277, 680-685.

LAI, Y. K. AND SCANDALIOS, J. G. 1980. Genetic determination of the developmental program for maize scutellar alcohol dehydrogenase: involvement of a recessive trans-acting temporal regulatory gene. Dev. Genet., 1, 311-324.

LAURIE, C. C., HEATH, E. M., JACOBSON, J. W. AND THOMSON, M. S. 1990. Genetic basis of the difference in alcohol 
dehydrogenase expression between Drosophila melanogaster and Drosophila simulans. Proc. Natl. Acad. Sci. U.S.A., 87, 9674-9678.

LAURIE-AHLBERG, C. C., MARONI, G., BEWLEY, G. C., LUCCHESI, J. C. AND WEIR, B. S. 1980. Quantitative genetic variation of enzyme activities in natural populations of Drosophila melanogaster. Proc. Natl. Acad. Sci. U.S.A., 77, 1073-1077.

LAURIE-AHLBERG, C. C., WILTON, A. N., CURTSINGER, J. W. AND EMIGH, T. H. 1982. Naturally occuring enzyme activity variation in Drosophila melanogaster I. Sources of variation for 23 enzymes. Genetics, 102, 191-206.

LINEWEAVER, H. AND BURK, D. 1934. The determination of enzyme dissociation constants. J. Am. Chem. Soc., 56, 658-666.

MCDONALD, J. F. 1983. The molecular basis of adaptation: a critical review of relevant ideas and observations. Ann. Rev. Ecol. Syst., 14, 77-102.

MCDONALD, J. F. AND AVISE, J. C. 1976. Evidence for the adaptive significance of enzyme activity levels. Interspecific activity levels of GPDH and ADH in Drosophila. Biochem. Genet., 14, 347-355.

MCKENZIE, J. A. AND PARSONS, P. A. 1972. Alcohol tolerance: an ecological parameter in the reletive success of Drosophila melanogaster and Drosophila simulans. Oecologia, 10, 373-388.

MANCINI, G., CARBONARA, A. O. AND HEREMANS, J. F. 1965. Immunochemical quantification of antigens by single radial immunodiffusion. Immunochemistry, 2, 235-254.
Ranganayakulu, G. 1990. Regulation of Tissue Specific Expression of Alcohol Dehydrogenase in the virilis Group of Drosophila. Ph.D Thesis, University of Hyderabad, India.

RANGANAYAKULU, G., KIRKPATRICK, R. B., MARTIN, P. F. AND REDDY, A. R. 1991. Species specific differences in tissue specific expression of alcohol dehydrogenase are under the control of complex cis-acting loci: evidence from Drosophila hybrids. Biochem. Genet., 29, 577-592.

SCHWARTZ, M., GERACE, L., O'DONNELL, J. M. AND SOFER, W. 1975. Drosophila alcohol dehydrogenase: origin of the multiple forms. In: Market, C. L. (ed.) Isozymes, vol. 1, pp. 725-751. Academic Press, New York.

SOFER, w. AND URSPRUNG, H. 1968. Drosophila alcohol dehydrogenase: purification and partial characterization. J. Biol. Chem., 243, 3110-3115.

SPIETH, H. T. 1979. The virilis group of Drosophila and the beaver castor. Am. Nat., 114, 312-316.

STEWART, C. B., SCHILLING, J. W. AND WILSON, A. C. 1987. Adaptive evolution in the stomach lysozymes of foregut fermenters. Nature, 330, 401-404.

THROCKMORTON, L. H. 1975. The phylogeny, ecology, and geography of Drosophila. In: King, R. C. (ed.) Handbook of Genetics, vol. 3, pp. 421-469. Plenum Press, New York. WEBER, K., PRINGLE, J. R. AND OSBORNE, M. 1972. Measurement of molecular weights by electrophoresis on SDS-acrylamide gels. Methods Enzymol., 26, 3-27.

WILSON, A. C., CARLSON, S. S. AND WHITE, T. J. 1977. Biochemical evolution. Ann. Rev. Biochem., 46, 473-639. 